Article

\title{
Reduced Graphene Oxide Embedded with MQ Silicone Resin Nano-Aggregates for Silicone Rubber Composites with Enhanced Thermal Conductivity and Mechanical Performance
}

\author{
Weijie Liang ${ }^{1, *,+} \mathbb{D}$, Xin Ge ${ }^{2,+}$, Jianfang Ge ${ }^{2, *}$, Tiehu Li ${ }^{1, *}$, Tingkai Zhao ${ }^{1} \mathbb{D}$, Xunjun Chen ${ }^{2}{ }^{(}$, \\ Yaozhen Song ${ }^{2}$, Yingde Cui ${ }^{3}$, Muhammad Khan ${ }^{1}$, Jianye $\mathrm{Ji}^{2}$, Xiaoyan Pang ${ }^{2}$ and Ruoling Liu ${ }^{2}$ \\ 1 Shaanxi Engineering Laboratory of Graphene New Carbon Materials and Applications, School of Materials \\ Science and Engineering, Northwestern Polytechnical University, Xi'an 710072, \\ China;ztk-xjtu@163.com (T.Z.); mkhan@mail.nwpu.edu.cn (M.K.) \\ 2 Guangdong Engineering Research Center of Silicone Electronic Fine Chemicals, College of Chemistry and \\ Chemical Engineering, Zhongkai University of Agriculture and Engineering, Guangzhou 510225, China; \\ 18011779939@163.com (X.G.); cxj.qiao@163.com (X.C.); yzsong@zhku.edu.cn (Y.S.); jjyjasonky@163.com (J.J.); \\ shelly_pxy@163.com (X.P.); liuruoling2018@163.com (R.L.) \\ 3 Guangzhou Vocational College of Science and Technology, Guangzhou 510550, China; 13602880087@139.com \\ * Correspondence: leungvijer@163.com (W.L.); ge650704@163.com (J.G.); litiehu@nwpu.edu.cn (T.L.) \\ + These authors contribute equally to this work.
}

Received: 14 October 2018; Accepted: 6 November 2018; Published: 12 November 2018

\begin{abstract}
With developments of the electronics industry, more components are being included in electronic devices, which has led to challenges in thermal management. Using reduced graphene oxide embedded with MQ silicone resin (RGO/MQ) nano-aggregates as the composite filler and silicone rubber (SR) as the matrix, a simple approach is designed to prepare RGO/MQ/SR composites. Reduced graphene oxide (RGO) was first used as a substrate for the growth of MQ silicone resin by hybridization, forming sandwich-like micro structured RGO/MQ nano-aggregates successfully. Then, RGO/MQ was integrated into $\alpha, \omega$-dihydroxylpolydimethylsiloxane based on the in situ solvent-free blending method, followed by condensation and vulcanization, fabricating the final $\mathrm{RGO} / \mathrm{MQ} / \mathrm{SR}$ composites. The effective strategy could enhance the adaptability between graphene and silicone matrix under external stimuli at room temperature by embedding nanoscale MQ into the interface of graphene/silicone as the buffer layer. Obvious improvements were found in both thermal conductivity and mechanical properties due to excellent dispersion and interfacial compatibility of $\mathrm{RGO} / \mathrm{MQ}$ in the host materials. These attractive results suggest that this RGO/MQ/SR composite has potential as a thermal interface material for heat dissipation applications.
\end{abstract}

Keywords: reduced graphene oxide; MQ silicone resin; silicone rubber composites; thermal conductivity; mechanical properties

\section{Introduction}

Silicone rubber has received considerable attention because of unique properties, such as the excellent environmental adaptivity of polydimethylsiloxane within a broad temperature range, resistance to oxidative degradation, low toxicity and high chemical stability [1-3]. Accordingly, it has been widely applied in a variety of settings, such as the aerospace industry, electronics, medical treatment and commodity manufacturing. Among most applications, the high performance of silicone rubber mainly relies on the addition of functional fillers [4-8]. Therefore, it is important to choose appropriate fillers to cater to the specific application requirements of silicone rubber. In recent 
years, much research interest has been paid to introducing composite fillers to improve the specific performance of silicone rubber [9-12]. However, uneven dispersion of fillers is a significant challenge to filling and enhancing composites.

Graphene has attracted extensive interest since it was first exfoliated in $2004[13,14]$. Due to its two-dimensional (2D) characteristics with a monolayer of carbon atoms all $\mathrm{sp}^{2}$ bonded in a hybridized structure, it exhibits the attractive properties of a large theoretical specific surface area $\left(2675 \mathrm{~m}^{2} \cdot \mathrm{g}^{-1}\right)$, excellent chemical stability, high electrical and thermal conductivity and outstanding mechanical strength [15]. Thus, it is utilized in abroad range of potential applications, including chemical sensors, energy storage and conversion, thermal interface materials and structure materials. Recently, silicone rubber filled with graphene has been reported [16-20]. The incorporation of graphene into silicone rubber has shown enhanced microwave absorption properties, electrical conductivity, energy storage, heat conduction and mechanical performance. However, the optimal enhancement in graphene-based silicone rubber has not been fully achieved due to insufficient dispersion and poor interfacial compatibility. Hence, it is necessary to modify graphene to achieve high dispersion and strong interface interactions with $\alpha, \omega$-dihydroxyl polydimethylsiloxane (PDMS) in the matrix.

$\mathrm{MQ}$ silicone resin (MQ) possesses a double-layer compact globular structure and is an important commercial silicone material that consists of a single functional siloxane chain unit $\left(\mathrm{R}_{3} \mathrm{SiO}_{1 / 2}\right.$, i.e., $\mathrm{M})$ and four functional siloxane chain units $\left(\mathrm{SiO}_{4 / 2}\right.$, i.e., Q) [21]. It has a host of excellent properties, such as hydrolysis resistance, antifriction, weathering and ageing resistance, film-forming ability, and radiation resistance, making it suitable for a wide range of applications (e.g., pressure-sensitive adhesives, encapsulations, coatings and personal care products). Given the good compatibility between $\mathrm{MQ}$ and polysiloxane, MQ is widely used in industrial silicone applications as a reinforcing filler for elastomers due to its silica content and macroscopic particle-like structure. Although a lot of application studies of MQ are reported in literature [22-24], there are few reports on silicone rubber filled with combinations of MQ and other kinds of fillers [25,26].

Combining advantages of both graphene and $\mathrm{MQ}$ may be an absorbing and promising alternative to fabricating high-performance silicone rubber. There are no related reports on silicone rubber (SR) composites using graphene/MQ nanocomposite as functional fillers. In this work, reduced graphene oxide embedded with $\mathrm{MQ}(\mathrm{RGO} / \mathrm{MQ})$ nano-aggregates was fabricated by hybridization of MQ nanospheres on the surface of reduced graphene oxide (RGO). The detailed synthesis route, as well as the involved morphology and structure of the as-prepared $R G O / M Q$, are presented. The RGO/MQ was incorporated into silicone rubber matrix to form RGO/MQ/SR composites, and performance relating to thermal conductivity and mechanical strength of composites was investigated. The straightforward strategy for preparing RGO/MQ/SR composite does not only make full use of the compatibility between $M Q$ and silicone rubber to improve dispersion and interfacial compatibility between graphene and silicone rubber, but it also ensures full use of RGO/MQ to achieve better thermal conductivity and mechanical properties of composites. The fabricated RGO/MQ/SR composite showed potential application in thermal interface materials. The impact of RGO/MQ on the other properties of silicone rubber composites will be explored systematically in a later study.

\section{Materials and Methods}

\subsection{Materials}

Sulfuric acid (analytical purity, 98\%) was provided by Tianjin Third Chemical Factory (Tianjin, China). Anhydrous ethanol (EtOH, AR), hydrochloric acid ( $\mathrm{HCl}, \mathrm{AR})$, toluene (AR), sodium nitrate $\left(\mathrm{NaNO}_{3}, \mathrm{AR}\right)$, potassium permanganate $\left(\mathrm{KMnO}_{4}, \mathrm{AR}\right)$ and hydrogen peroxide $\left(\mathrm{H}_{2} \mathrm{O}_{2}, \mathrm{AR}\right)$ were purchased from Damao Chemical Reagent Factory (Tianjin, China). Hexamethyldisiloxane (MM, industrial grade), tetraethyl orthosilicate (TEOS, industrial grade), methyltrimethoxylsilane (MTMS, industrial grade) and dibutyltindilaurate (DBTDL, industrial grade) were purchased from Hangzhou Guibao Chemical Co., Ltd. (Hangzhou, China). PDMS (industrial grade) with viscosities of $20 \mathrm{~Pa} \cdot \mathrm{s}$ was 
produced by Foshan Lin Si silicone Materials Co., Ltd. (Foshan, China). Flake graphite was supplied by Qingdao Dongkai Graphite Co., Ltd. (Qingdao, China).

\subsection{Synthesis of $R G O$}

Graphene oxide (GO) was prepared by modified Hummers method. Firstly, $5 \mathrm{~g}$ flake graphite and $5 \mathrm{~g} \mathrm{NaNO}_{3}$ mixed with $250 \mathrm{~mL} 98 \mathrm{wt} \% \mathrm{H}_{2} \mathrm{SO}_{4}$ were stirred in a round bottom three-neck flask in ice water bath. Then, $30 \mathrm{~g} \mathrm{KMnO}_{4}$ was added slowly to the solution maintainedat about $0{ }^{\circ} \mathrm{C}$ to avoid the risk of explosion caused by the redox reaction. The reaction was maintained at this temperature for $1 \mathrm{~h}$ with continuous agitation. The flask with the mixture was transferred to the oil bath at $35 \pm 5{ }^{\circ} \mathrm{C}$, stirring for $1 \mathrm{~h}$. Afterwards, the temperature of the oil bath was increased to $95 \pm 5{ }^{\circ} \mathrm{C}$ and $400 \mathrm{~mL}$ deionized water was decanted into the solution gradually. After $30 \mathrm{~min}, 1000 \mathrm{~mL}$ deionized water was poured into the flask. The solution changed to a luminous yellow color during dropwise addition of $30 \mathrm{~mL} \mathrm{H}_{2} \mathrm{O}_{2}$ (volume ratio: $35 \%$ ). The resulting sample was washed with deionized water and ethanol until natural $\mathrm{pH}$ value and filtered over a microfiltration membrane $(0.45 \mu \mathrm{m})$. GO was dried by freeze-drying process $\left(-55^{\circ} \mathrm{C}\right.$ for $12 \mathrm{~h}$ ) and ground by ball grinding technology. Then, GO powders were positioned in a quartz tube reactor under a flow of argon at $600^{\circ} \mathrm{C}$. After thermal reduction, RGO was collected for further application.

\subsection{Synthesis of $M Q$}

MQ was synthesized by a hydrolysis-polycondensation method. Briefly, first, $71.3 \mathrm{~g}$ MM mixed with the mixtures of $6.3 \mathrm{~mL} \mathrm{EtOH}, 38.2 \mathrm{~mL} \mathrm{H}_{2} \mathrm{O}$ and $5.9 \mathrm{~mL} \mathrm{HCl}$ were stirred by power basic stirrer at room temperature for $30 \mathrm{~min}$. Then the temperature of the oil bath was increased to $60{ }^{\circ} \mathrm{C}$ and meanwhile $115.5 \mathrm{~g}$ TEOS was added into the solution drop by drop. The reaction under stirring and refluxing was maintained at this temperature for $3 \mathrm{~h}$. After the reaction, $50 \mathrm{~mL}$ toluene was poured into the solution to extract MQ. The MQ-toluene solution was washed with deionized water until neutral. Finally, MQ was obtained via decompression distillation and drying process.

\subsection{Synthesis of $R G O / M Q$}

The RGO/MQ was directly fabricated by hybridization. The MQ was firstly dissolved into anhydrous ethanol ultrasonically for $10 \mathrm{~min}$ at room temperature. Then the RGO was added into the solution by ultrasonic dispersion for $2 \mathrm{~h}$. The mass ratio of MQ and RGO was 10:1. After forming homogeneous dispersion, the distilled water was dripped into it slowly under strong agitation in order to promote the growth of MQ on the surface of graphene. Some gel appeared in the mixture. Eventually, the mixed system yielded a slurry. Afterwards, the slurry was stirred constantly for $1 \mathrm{~h}$. Subsequently, it was treated by vacuum suction filtration to obtain wet RGO/MQ. Finally, RGO/MQ was dried by vacuum drying at $60^{\circ} \mathrm{C}$ for $24 \mathrm{~h}$.

\subsection{Preparation of $R G O / M Q / S R C o m p o s i t e s$}

Firstly, PDMS (100.00 g) was compounded with the RGO/MQ (0, 5, 10, 15, 20, or $25 \mathrm{~g})$ by three-roller machine. Then, the crosslinking agent, MTMS (2.5 g), was added and mixed. After that, the catalyst, DBTDL $(0.5 \mathrm{~g})$, was incorporated into the mixture. Having been homogenized, the mixture was cast into an open polytetrafluoroethylene (PTFE) mold to cure for more than $24 \mathrm{~h}$ at room temperature. The sample of RGO/MQ/SR composites was left standing for 7 days for more sufficient crosslinking before testing. Figure 1 provides the preparation process for RGO/MQ/SR composites. $\mathrm{MQ} / \mathrm{SR}$ composites and RGO/SR composites were prepared by the same method for comparison. 


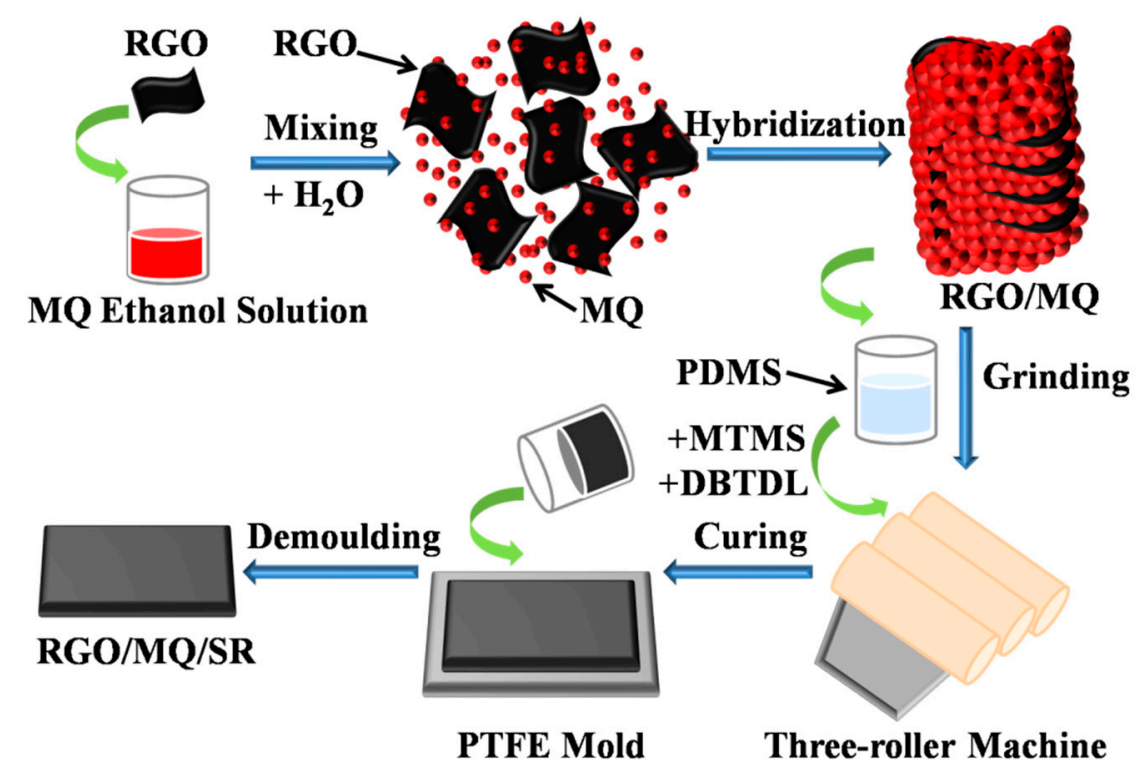

Figure 1. Scheme for the preparation of RGO/MQ/SR composites.

\subsection{Characterization}

Field emission scanning electron microscope (SEM, SU8220, Hitachi, Tokyo, Japan), X-ray diffraction patterns (XRD, D8 ADVANCE, Bruker AXS, Karlsruhe, Germany), Raman scattering spectrum (LabRAM HR800, HORIBA Scientific, Lat Krabang, Thailand), Fourier transform infrared spectroscopy (FT-IR, Perkin Elmer Spectrum 100, Shelton, DC, USA) was employed for qualitative analyses on the surface morphology, structural characteristics and component composition of MQ, GRO and RGO/MQ. The surface morphologies of cross-sections of RGO/MQ/SR composites and MQ/SR composites were characterized by scanning electron microscopy (EVO18, Carl Zeiss, Jena, Germany). Thermal conductivity of the composites was measured using a universal thermal conductivity meter (TC3000, Xiatech, Xi'an, China), and the dimension of specimens was $50 \times 40 \times 2 \mathrm{~mm}^{3}$. Shore A hardness was examined by LX-A Shore hardness equipment for rubber (Shanghai Precision Instruments Co., Ltd., Shanghai, China). Tensile strength and elongation at break were measured by a universal testing machine (AGS-1, Shimadzu, Kyoto, Japan) according to the GB/T 528-2009 standard.

\section{Results and Discussion}

\subsection{Morphology and Structure of the RGO/MQ}

Figure 2a,c,e shows SEM images of RGO, MQ and RGO/MQ, and Figure $2 b, d, f$ shows respective enlargements. The structure of fluffy and multiple layers is shown in Figure 2a after thermal exfoliation and reduction of GO. Many folds on the surface can be seen clearly in Figure $2 b$. The edges of RGO partially curl. Figure 2c displays the microstructure of pure MQ in the form of nanoparticles. The morphology of the pristine nanoparticles is spherical. The average diameter of the spherical particles is around $300 \mathrm{~nm}$. Figure $2 \mathrm{~d}$ is the enlarged picture of Figure $2 \mathrm{c}$, showing the aggregation among nanoparticles. The shapes of the aggregation are different due to randomness of contacting. In Figure 2e it can be seen that agglomerated MQ spheres as the outer modified coating adhere to the surface of lamellar RGO as the internal skeleton. Figure $2 \mathrm{f}$ is the high-magnification SEM image of the selected rectangular region of RGO/MQ. In addition to MQ covering RGO directly and densely, some MQ clusters partially fill the lacuna of RGO and lie on the edges of RGO, which demonstrates the existence of the intense interaction between MQ and RGO. This structure shows graphene more efficiently immersed into silicone matrix and provides the channel for heat conduction, as well as increasing the structure stability of composites. 

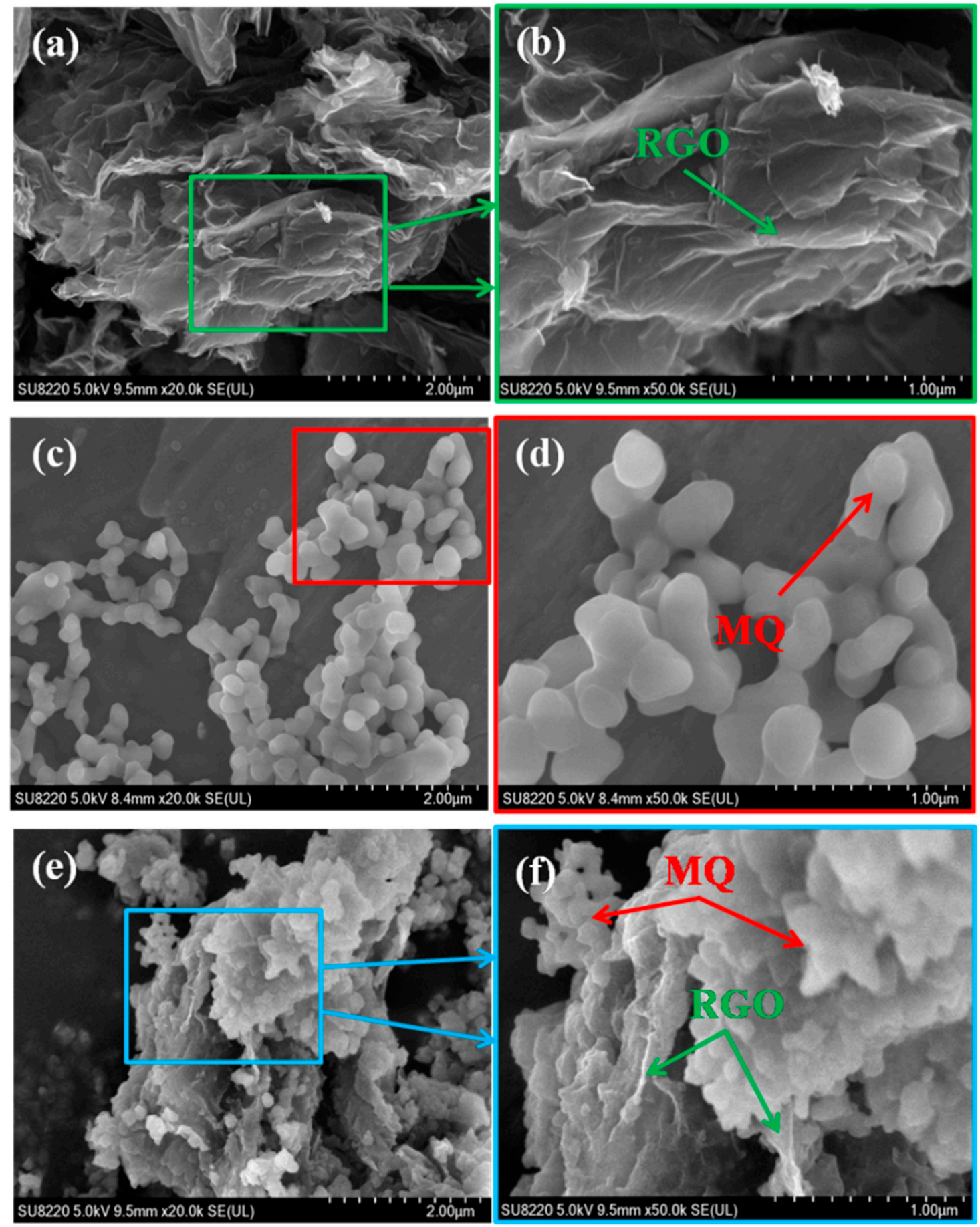

Figure 2. Scanning electron microscopy (SEM) images of (a,b) RGO, (c,d) MQ and (e,f) RGO/MQ at different magnifications.

The XRD patterns of RGO, MQ and RGO/MQ are presented in Figure 3. It can be seen that the RGO have a broad typical diffraction peak at $25.9^{\circ}$, which is typical of multilayered graphene [27], and signifies the graphene phase due to high temperature deoxidization. From the XRD pattern of $M Q$, obvious characteristic diffraction peaks cannot be found compared to diffuse X-ray peaks. As $2 \theta$ ranges from $12.8^{\circ}$ to $32.5^{\circ}$, diffuse $X$-ray peaks are centered at $17.5^{\circ}$ and $25.0^{\circ}$, respectively. This indicates MQ crystal structure is amorphous [26]. The RGO/MQ mainly displays diffuse X-ray peaks at $2 \theta=12.8-32.5^{\circ}$, which is a little stronger than that of MQ. The existence of weak diffraction peaks at $25.9^{\circ}$ and $43.6^{\circ}$ of RGO/MQ can be attributed to steric hindrance of MQ. Moreover, no 
obvious signs of a sharp peak of graphite at $26.6^{\circ}$ can be detected in the RGO/MQ [28]. On one hand, this is attributed to RGO after the introduction of MQ. On the other hand, the remarkable face-to-face stacking is broken because of the growth of $\mathrm{MQ}$ between the interlayer of RGO, demonstrating that RGO and MQ successfully constitute RGO/MQ.

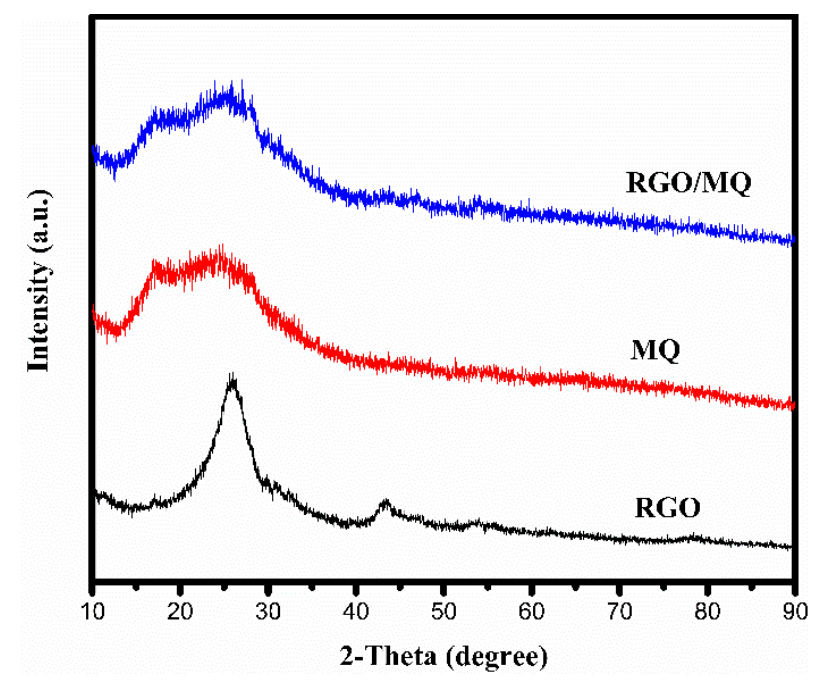

Figure 3. X-ray diffraction (XRD) patterns of RGO, MQ and RGO/MQ.

The Raman spectra of RGO, MQ and RGO/MQ silicone resin are shown in Figure 4a. The RGO curve exhibits two significant peaks in the 1352 and $1595 \mathrm{~cm}^{-1}$ regions, which are assigned to the D and $G$ bands of graphene, respectively. The $D$ peak is stronger than the $G$ peak, so the $I_{D} / I_{G}$ ratio of graphene is 1.24 for some structure defects and the edge effects of narrow width of graphene sheets [29]. The Raman spectra of MQ has four sharp peaks at 617, 694, 2918 and $2977 \mathrm{~cm}^{-1}$, corresponding to stretching vibration of $\mathrm{C}-\mathrm{Si}$, symmetrical stretching vibration of $\mathrm{SiC}_{2}$, symmetrical stretching vibration of $\mathrm{CH}_{3}$ and antisymmetrical stretching vibration of $\mathrm{CH}_{3}$, respectively [30]. Although symmetrical stretching vibration and asymmetrical stretching vibration signals of $\mathrm{Si}-\mathrm{O}-\mathrm{Si}$ cannot be easily observed on the Raman spectra of MQ, they can be easily found in the FT-IR spectra of MQ. For the case of $\mathrm{RGO} / \mathrm{MQ}$, the reemerging peaks of $\mathrm{C}-\mathrm{Si}, \mathrm{SiC}_{2}$ and $\mathrm{CH}_{3}$ and the weaker intensity of $\mathrm{D}$ and $\mathrm{G}$ bands of graphene compared to RGO demonstrate that MQ is well dispersed on the surface of RGO.

For better understanding of the interaction between RGO and MQ, the FT-IR spectra of RGO, $\mathrm{MQ}$ and RGO/MQ are compared in Figure $4 \mathrm{~b}$. For the case of RGO, the broad and strong peak at $3435 \mathrm{~cm}^{-1}$ is assigned to the characteristic stretching vibration of $\mathrm{O}-\mathrm{H}$, while the weak bands at 1632 and $1129 \mathrm{~cm}^{-1}$ are stretching vibration absorption peaks of $\mathrm{C}=\mathrm{C}$ and $\mathrm{C}-\mathrm{O}$, respectively [31]. The presence of a small number of residual oxygen-containing functional groups indicates that it is hard to remove all the oxygenic groups by thermal reduction. The curve of MQ displays spectrum information of its structure. The small sharp peak centered at $3705 \mathrm{~cm}^{-1}$ and the broad absorption peak at $3448 \mathrm{~cm}^{-1}$ are due to stretching vibration of free $\mathrm{Si}-\mathrm{OH}$ and $\mathrm{Si}-\mathrm{OH}$ with hydrogen-bonded association, respectively [32]. The two sharp peaks at 2961 and $2901 \mathrm{~cm}^{-1}$ are related to the $\mathrm{C}-\mathrm{H}$ asymmetric and symmetric stretching vibrations signal of $\mathrm{Si}-\mathrm{CH}_{3}$. The bands of $\mathrm{Me}_{3} \mathrm{SiO}$ are 1255, 845 , and $757 \mathrm{~cm}^{-1}$. The peak with strong and broad shoulders located at $1080 \mathrm{~cm}^{-1}$ is asymmetric stretching vibration of $\mathrm{Si}-\mathrm{O}-\mathrm{Si}$ [33]. These peaks all confirm that it is a sample of pure MQ. The spectra of RGO/MQ shows most of the characteristic peaks of MQ due to its sandwich-like microstructure; there is a minor low intensity peak at around $1632 \mathrm{~cm}^{-1}$ corresponding to that of RGO, which indicates that MQ and RGO are well combined. 

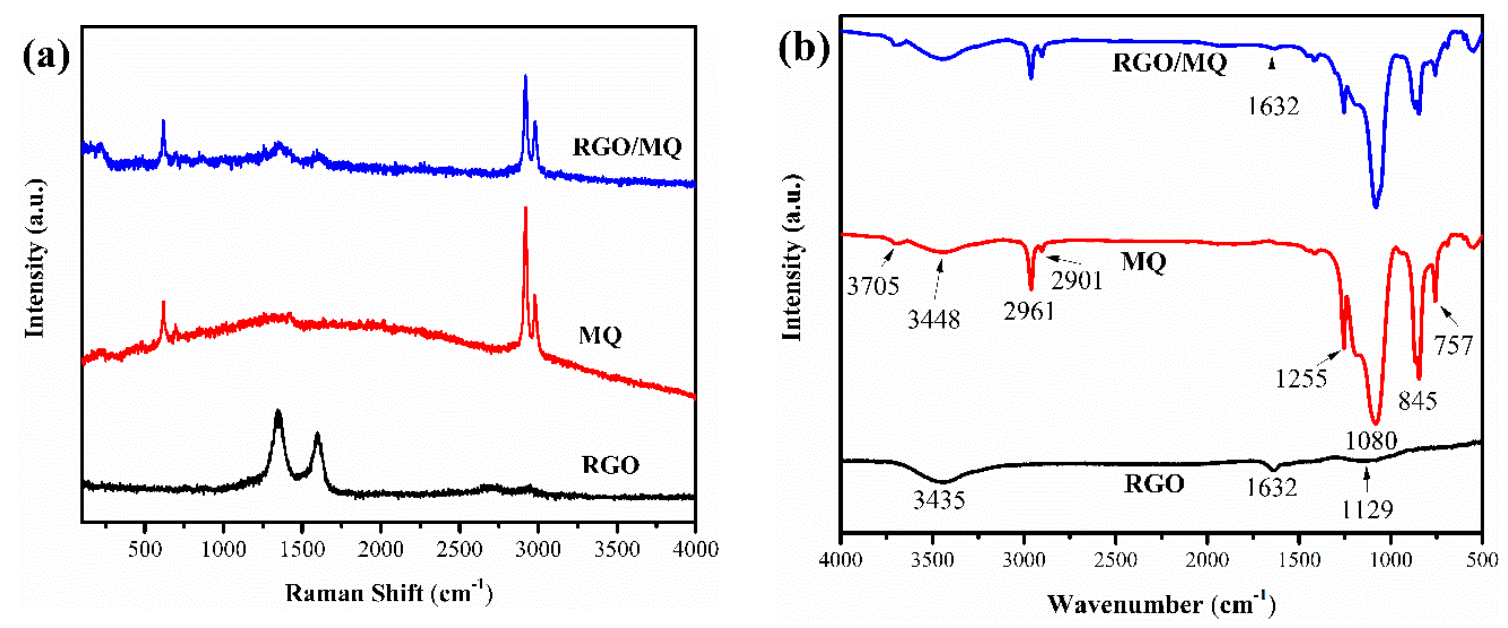

Figure 4. (a) Raman spectra of RGO, MQ and RGO/MQ; (b) Fourier transform infrared spectroscopy (FT-IR) spectra of RGO, MQ and RGO/MQ.

\subsection{Morphology of the RGO/MQ/SR Composites}

To fabricate polymer composites, we chose silicone rubber as a flexible matrix and incorporated the $\mathrm{RGO} / \mathrm{MQ}$ nano-aggregates and pristine $\mathrm{MQ}$ by the in situ solvent-free blending method to investigate their morphology. The morphology of composite cross-sectional surfaces was studied by SEM. Figure 5 shows SEM images of MQ/SR composites and RGO/MQ/SR composites. Cracks found on the surface of MQ/SR composites are shown in Figure $5 \mathrm{a}, \mathrm{b}$. As a result of the curing reaction of silicone rubber between MQ and PDMS, MQ is not observable in the images. A uniform distribution of small white spots is observable on the surface of RGO/MQ/SR composites as shown in Figure $5 c$. Figure $5 d$ is the enlarged image of Figure 5c. In Figure 5d, RGO can be observed on the surface of silicone rubber. This observation indicates the small white spots in Figure $5 c$ are RGO. As seen in Figure $5 d$, there are no apparent signs of microcracks and holes at interfacial regions between graphene and silicone rubber. As observed in Figure 5c,d, few cavities can be found on the surface of silicone rubber filled with RGO/MQ because of the good compatibility and strong interfacial interactions between graphene and polymer matrix, with the help of $\mathrm{MQ}$, according to the basis of the hole theory [34]. Graphene is equally distributed rather than self-aggregated in the internal polymer matrix, which can promote the performance of composites. The result explains that MQ can effectively facilitate the dispersion of graphene.

\subsection{Thermal Conductivity of the RGO/MQ/SR Composites}

The result of thermal conductivity tests at room temperature of the composites formed by adding different contents of MQ and RGO/MQ are depicted in Figure 6a. With an increased loading amount of MQ, the thermal conductivity of MQ/SR composites is about $0.20 \mathrm{~W} \cdot \mathrm{m}^{-1} \cdot \mathrm{K}^{-1}$ and does not show a substantial change compared to neat silicone rubber without filled MQ. The conduction of heat relies on atomic thermal vibration along the macromolecule chains in the pure silicone rubber. MQ can react with PDMS to improve the density of organic silicone polymeric chain crosslinking, which is not beneficial to heighten the heat transfer capability of phonons of macromolecule chains. Therefore, $\mathrm{MQ}$ is not alone suitable as a thermal conductive filler applied to polymer matrices due to its poor thermal conductivity. It is clear that the addition of RGO/MQ results in an increase in thermal conductivity of silicone rubber, which can be attributed to the incorporation of RGO [35]. With content of 5 and $10 \mathrm{wt} \% \mathrm{RGO} / \mathrm{MQ}, \mathrm{RGO} / \mathrm{MQ} / \mathrm{SR}$ composites exhibit a thermal conductivity enhancement of approximately $35 \%$ and $65 \%$, respectively. At low RGO/MQ loading, the RGO content of filler was not high enough to accelerate thermal conductivity. This is because RGO does not have good contact with the silicone rubber, but it does contribute to the spreading of phonons in the system. When the RGO/MQ content increases further, the thermal conductivity enhancement of RGO/MQ/SR 
composites is $115 \%, 140 \%$ and $155 \%$ at the content of 15, 20 and $25 \mathrm{wt} \%$, respectively. Owing to the increase in the content of RGO/MQ, more graphene appears in the matrix. An increase in the number of thermal conductive pathways is generated, which is beneficial for forming dense thermal conductive networks. The maximum thermal conductivity of $\mathrm{RGO} / \mathrm{MQ} / \mathrm{SR}$ reaches $0.51 \mathrm{~W} \cdot \mathrm{m}^{-1} \cdot \mathrm{K}^{-1}$ in the filler content range, which is significantly higher than that of pure silicone rubber. The heat conduction networks play a major role in the thermal conductivity enhancement due to the effective reduction of the thermal resistance of matrix [19].
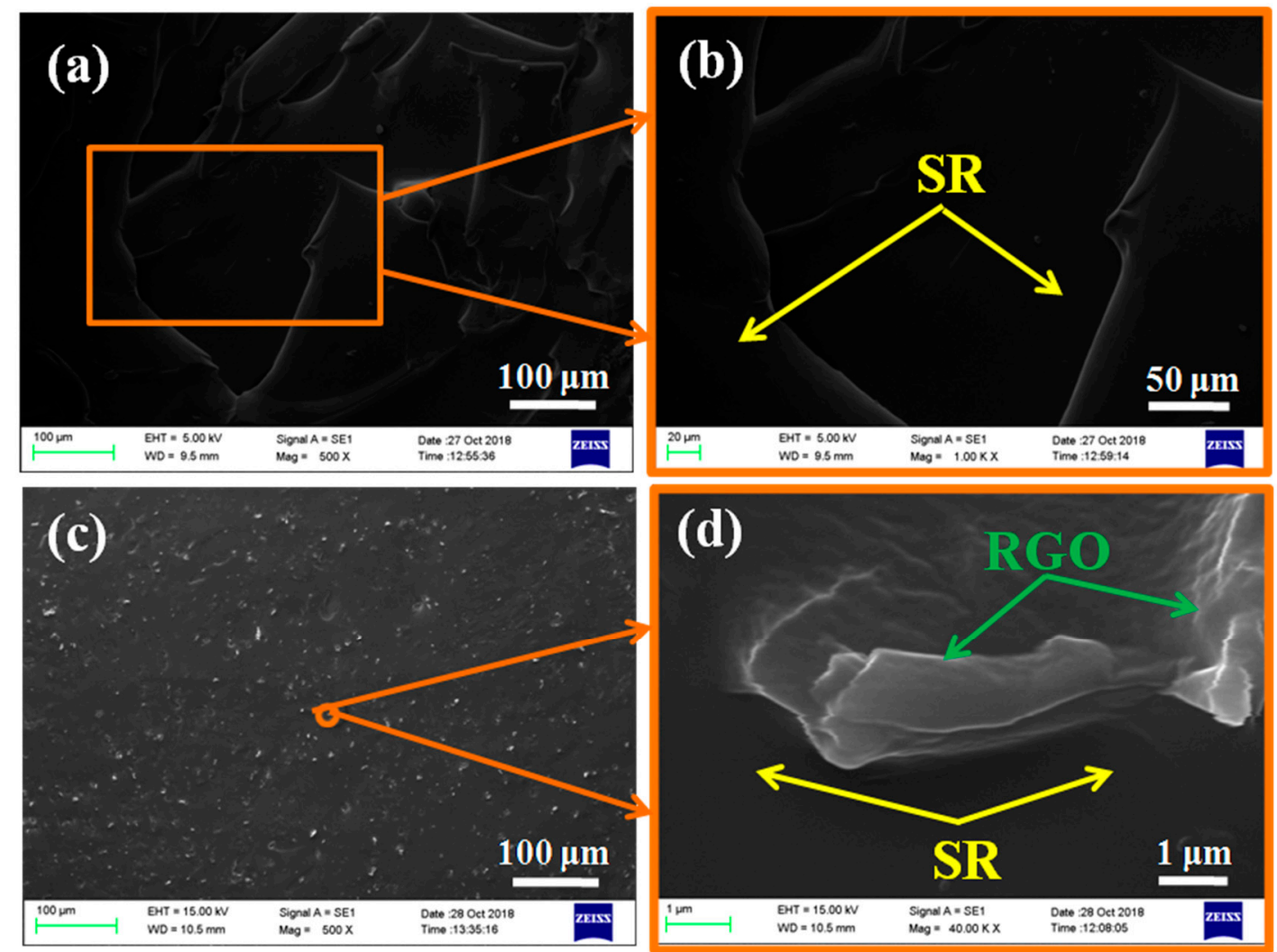

Figure 5. SEM images of $(\mathbf{a}, \mathbf{b}) \mathrm{MQ} / \mathrm{SR}$ composites and (c,d) RGO/MQ/SR composites at different magnifications.
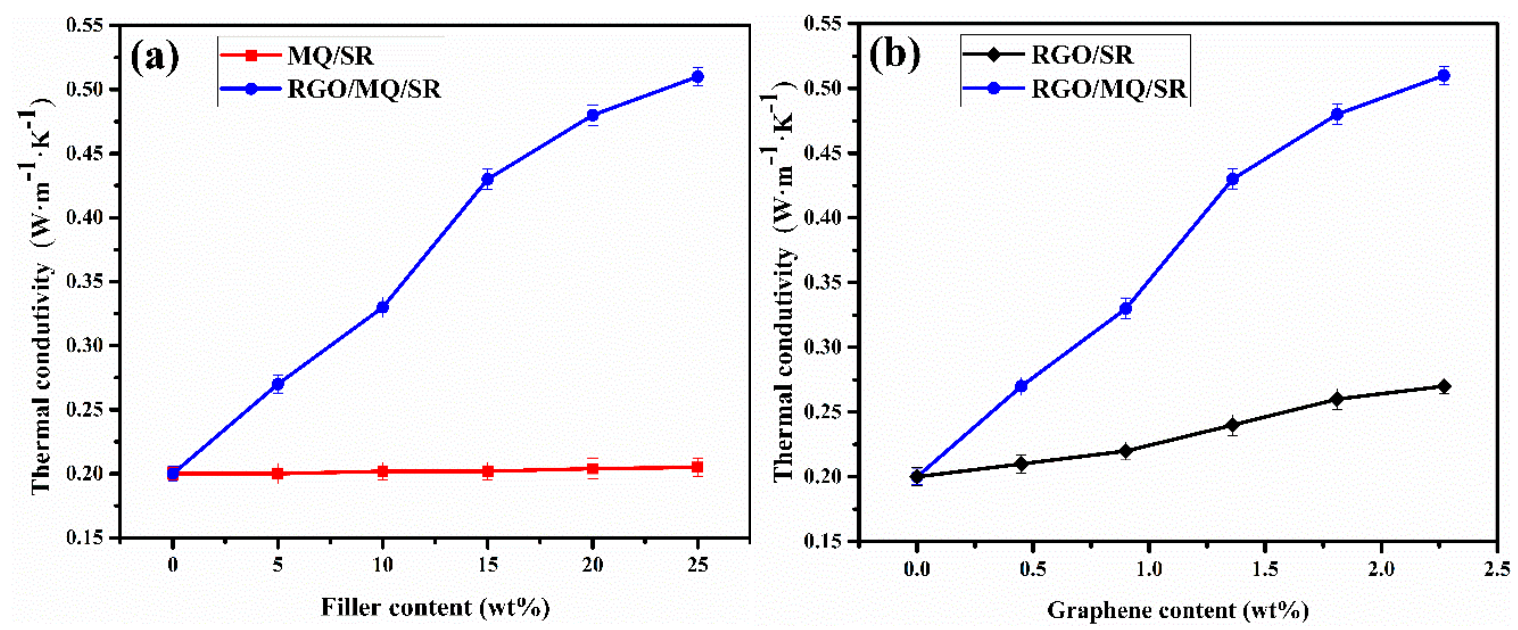

Figure 6. (a) Thermal conductivity of MQ/SR composites and RGO/MQ/SR composites with different filler contents; (b) thermal conductivity of RGO/MQ/SR composites and RGO/SR composites with different graphene contents. 
Figure $6 \mathrm{~b}$ represents the thermal conductivity of RGO/SR composites and RGO/MQ/SR composites in accordance with the increments of graphene loadings. The thermal conductivity of $\mathrm{RGO} / \mathrm{SR}$ composites increases slightly from 0.20 to $0.27 \mathrm{~W} \cdot \mathrm{m}^{-1} \cdot \mathrm{K}^{-1}$ with respect to the increasing loading amount of RGO. This result reflects the poor dispersion and weak interaction between RGO and silicone rubber. By contrast, the thermal conductivity of RGO/MQ/SR composites with the same amount of RGO shows a considerable increase. Graphene can form effective thermal conductive pathways in the matrix, accompanying a homogeneous dispersion due to good interfacial compatibility between graphene and matrix assisted by MQ.

In contrast to other previous work, the results of thermal conductivity show greater improvement, shown in Figure 7. Our work shows thermal conductivity of RGO/MQ/SR composites with a lower graphene content are competitive with those of other graphene/silicone rubber composites previously reported in the literature $[17,19,35-41]$. The improved thermal conductivity demonstrates that sandwich-like micro structured RGO/MQ can motivate the dispersion of RGO in the matrix which fully utilizes the thermal conductance of graphene. The achievement of RGO/MQ/SR composites can be exploited for thermal interface materials for thermal management.

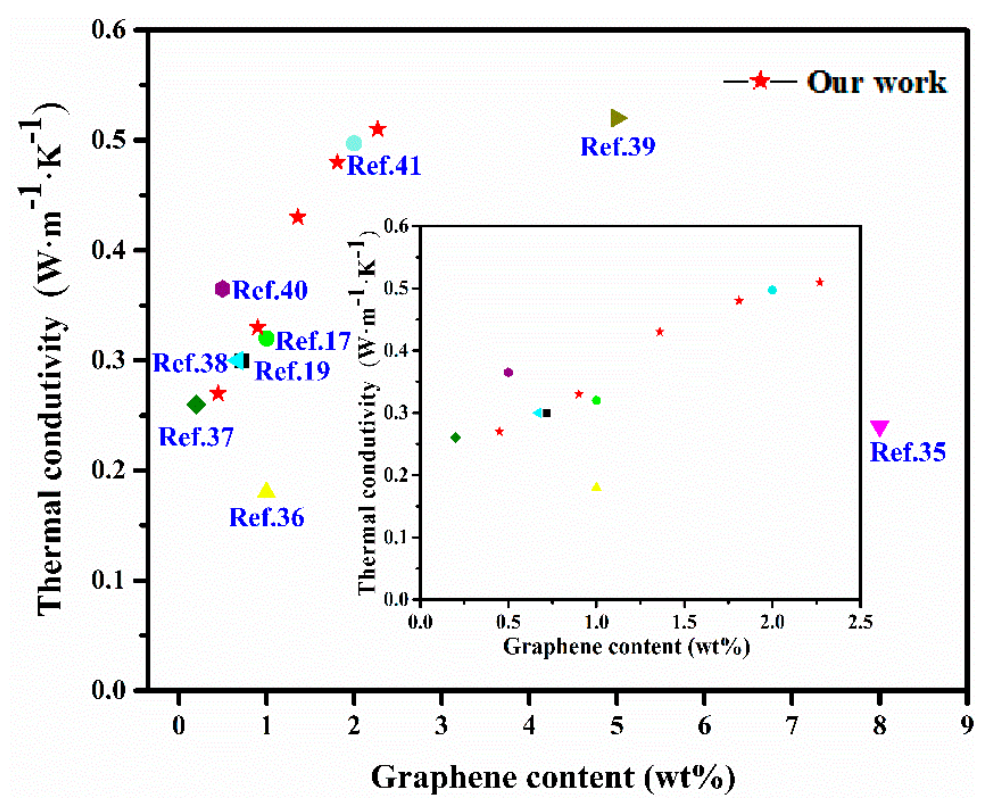

Figure 7. Comparison of thermal conductivity of graphene/silicone rubber composites presented in literature and our work.

\subsection{Mechanical Properties of the RGO/MQ/SR Composites}

To compare the effect of filler type and content, investigations of mechanical properties of MQ/SR and RGO/MQ/SR composites were conducted. Shore A hardness was tested to assess the ability of composites to resist indentation by a hard object. As can be seen from Figure 8a, Shore A hardness of RGO/MQ/SR composites increases substantially with the increase of content of RGO/MQ in the experimental range, and is up to $254 \%$ and $281 \%$ harder with 20 and $25 \mathrm{wt} \%$ addition, respectively, which is much higher than for the corresponding MQ/SR composites. The excellent mechanical strength and very high aspect ratio of RGO, as the framework introduced into MQ, led to greater reinforcement in the resulting composites [42]. 

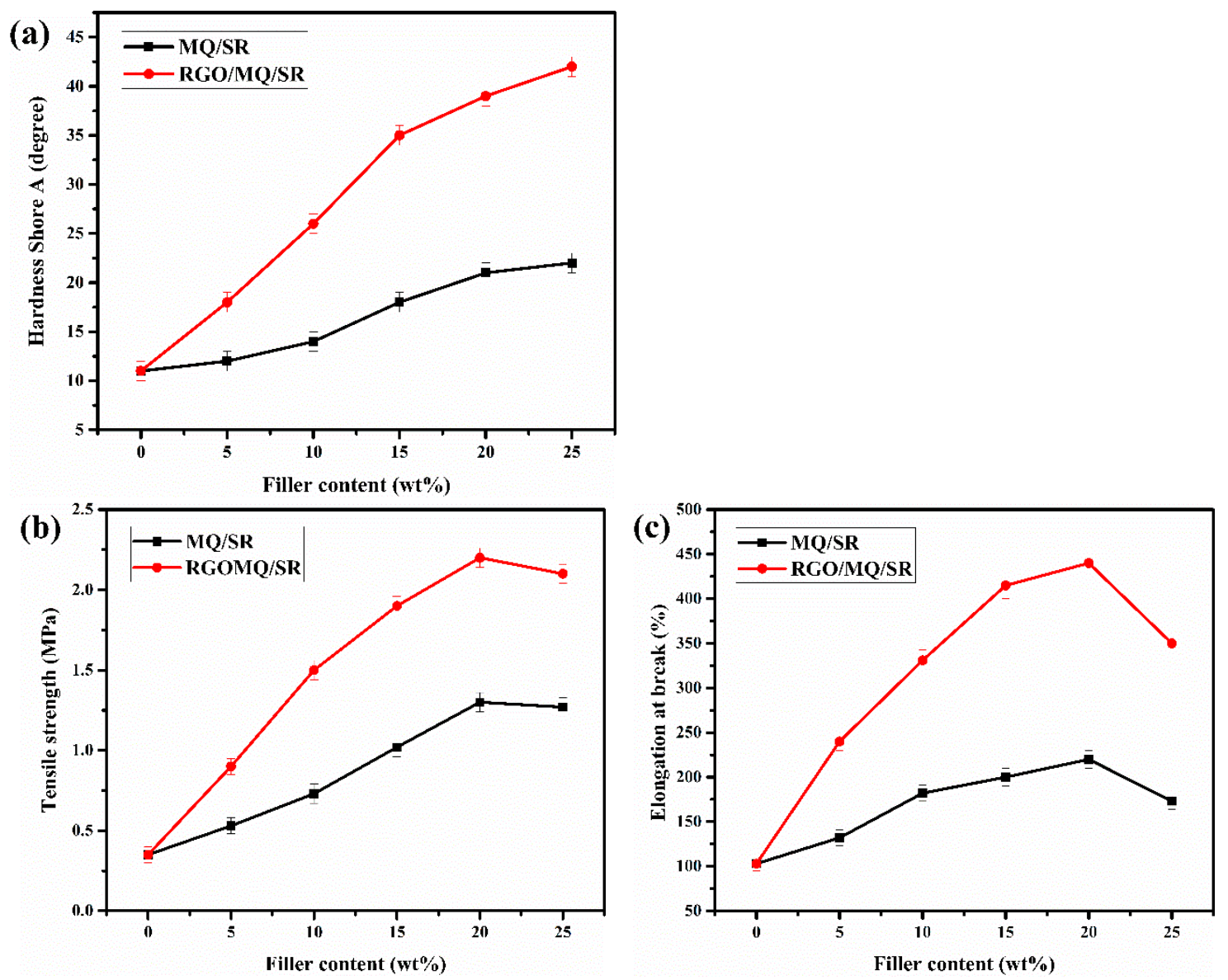

Figure 8. Effects of MQ and RGO/MQ content on (a) Shore A hardness, (b) tensile strength and (c) elongation at break of silicone rubber composites.

Tensile strength values were examined to study the ability of the as-prepared composites to resist permanent deformation and destruction, and the results are shown in Figure $8 \mathrm{~b}$. The tensile strength of MQ/SR composites increased with the increment of MQ from 0 to $20 \mathrm{wt} \%$, which can be attributed to the increase in crosslinking density [22] that occurs because the hydroxyl group of MQ can react with the terminal hydroxyl group of PDMS to form a crosslinking network by condensation in silicone rubber. For $\mathrm{RGO} / \mathrm{MQ} / \mathrm{SR}$ composites, the tensile strength value declined after rising to a maximum value of $2.2 \mathrm{MPa}(20 \mathrm{wt} \%)$, which was much higher than the $1.3 \mathrm{MPa}$ recorded for MQ-filled silicone rubber. When $\mathrm{RGO} / \mathrm{MQ}$ is integrated into silicone rubber, MQ acts as a bridge between the RGO and rubber matrix so that the compatibility of RGO with polysiloxane is greatly improved. Reducing the agglomeration of the graphene by $\mathrm{MQ}, \mathrm{RGO}$ can form reinforcing centers through physical entanglement with the chains of PDMS. Moreover, the effective interfacial interactions between RGO and PDMS promote the load transfer from rubber matrix to nanofiller. The synergistic effect between the crosslinking function generated by MQ and PDMS, and physical connection formed by RGO and PDMS, plays an important role in improving tensile strength of $\mathrm{RGO} / \mathrm{MQ} / \mathrm{SR}$ composites. Enhancement of tensile strength decreased at the filling ratio of $25 \mathrm{wt} \%$ of RGO/MQ, which might be due to filled RGO/MQ reaching a critical level and RGO beginning agglomeration. The poor dispersion of RGO weakens interaction with PDMS, and so obstructs the reinforcement of RGO/MQ/SR composites.

The elongation at break values was measured to survey the tensile processes before reaching the breaking point of the as-prepared polysiloxane matrices (Figure 8c). The elongation at break of silicone rubber first increases and then decreases with the increasing loading amount of MQ and $\mathrm{RGO} / \mathrm{MQ}$. At the same loading amount of filler, the elongation at break of RGO/MQ/SR composites 
was much greater than that of MQ/SR composites. The elongation at break of the RGO/MQ/SR composites increased from $103 \%$ to $440 \%$ when the RGO/MQ content rose from 0 to $20 \mathrm{wt} \%$. However, when the RGO/MQ content reached $25 \mathrm{wt} \%$, the elongation at break of RGO/MQ/SR composites decreased to $350 \%$. The decrease results from excessive crosslinking density mainly caused by MQ and insufficient dispersion generated by RGO between fillers and matrixes. Compared with that of pure SR, improvement in the mechanical properties of the filled SR was achieved on account of the packing type [43]. Comparing the fillers of $M Q$ and $R G O / M Q$, pristine $M Q$ presented the improved mechanical properties of the polysiloxane matrix, and RGO/MQ showed much greater improvement after introducing RGO as the dispersion supporter.

\section{Conclusions}

This study prepared RGO/MQ nano-aggregates by hybridization and then investigated the effect of RGO/MQ and pristine MQ loading on thermal conductivity and mechanical performance of the resulting silicone rubber composites. We found that RGO/MQ exhibited a sandwich-like microstructure. Furthermore, it was revealed that the addition of an optimal ratio of RGO/MQ to SR can simultaneously enhance thermal conductivity and mechanical performance of the resulting SR composites, which can be mainly attributed to excellent distribution of RGO/MQ and strong interfacial compatibility of the composites. The RGO/MQ/SR composites resulting from the addition of $20 \mathrm{wt}$ $\%$ RGO/MQ exhibited concurrent improvements in thermal conductivity, Shore A hardness, tensile strength and elongation at break of $140 \%, 254 \%, 528 \%$, and $327 \%$, respectively, compared to neat silicone rubber. In light of its solvent-free nature and these outstanding properties, RGO/MQ/SR composite is envisioned to have enormous potential as a thermal interface material in thermal management.

Author Contributions: This study was conducted by W.L., J.G., T.L. and X.G., with project support from J.G., T.L. and X.G. W.L. played a leading role in proposing the research. J.J., X.P. and R.L. prepared the draft of the paper, and all the other authors helped to revise it, including, T.Z., X.C., Y.C., Y.S. and M.K.

Funding: This work was funded by the Natural Science Foundation of China (51572221, 51672221), the Key Science and Technology Program of Shaanxi Province (2014K08-15), the Special Funds for Applied Science and Technology Research and Development of Guangdong Province (2015B090925022), the Guangdong Public Welfare Fund and Ability Construction Project (2016A010103037), Guangdong Science and Technology Project (2016B090930010) and Graduate Science and Technology Innovation Fund of Zhongkai University of Agriculture and Engineering (KJCX2017007).

Conflicts of Interest: The authors declare no conflict of interest.

\section{References}

1. Eduok, U.; Faye, D.; Szpunar, J. Recent developments and applications of protective silicone coatings: A review of PDMS functional materials. Prog. Org. Coat. 2017, 111, 124-163. [CrossRef]

2. Shit, S.C.; Shah, P. A review on silicone rubber. Natl. Acad. Sci. Lett. 2013, 36, 355-365. [CrossRef]

3. Zhang, Y. Preparation of high-temperature silicone rubber mold and its application in food industry. Adv. J. Food Sci. Technol. 2016, 12, 145-149. [CrossRef]

4. Li, X.; Zhang, D.; Chen, Y. Silicone rubber/hollow silica spheres composites with enhanced mechanical and electrical insulating performances. Mater. Lett. 2017, 205, 240-244. [CrossRef]

5. Wåhlander, M.; Nilsson, F.; Andersson, R.L.; Sanchez, C.C.; Taylor, N.; Carlmark, A.; Hillborg, H.; Malmström, E. Tailoring dielectric properties using designed polymer-grafted ZnO nanoparticles in silicone rubber. J. Mater. Chem. A 2017, 5, 14241-14258. [CrossRef]

6. Gao, B.; Xu, J.; Peng, J.; Kang, F.; Du, H.; Li, J.; Chiang, S.W.; Xu, C.; Hu, N.; Ning, X. Experimental and theoretical studies of effective thermal conductivity of composites made of silicone rubber and $\mathrm{Al}_{2} \mathrm{O}_{3}$ particles. Thermochim. Acta 2015, 614, 1-8. [CrossRef]

7. Namitha, L.K.; Ananthakumar, S.; Sebastian, M.T. Aluminum nitride filled flexible silicone rubber composites for microwave substrate applications. J. Mater. Sci. Mater. Electron. 2015, 26, 891-897. [CrossRef]

8. Zhang, Y.; Zeng, X.; Lai, X.; Li, H. Preparation of functionalized zirconium phosphate and its effect on the flame retardancy of silicone rubber. RSC Adv. 2018, 8, 111-121. [CrossRef] 
9. Xiao, W.; Lei, Y.; Xia, Z.; Chen, X.; Han, Y.; Nie, J. Effect of silver plating time on the properties of conductive silicone rubber filled with silver-coated carbonyl nickel powder. J. Alloys Compd. 2017, 724, 24-28. [CrossRef]

10. Lou, F.; Cheng, L.; Li, Q.; Wei, T.; Guan, X.; Guo, W. The combination of glass dust and glass fiber as fluxing agents for ceramifiable silicone rubber composites. RSC Adv. 2017, 7, 38805-38811. [CrossRef]

11. Ziraki, S.; Zebarjad, S.M.; Hadianfard, M.J. A study on the tensile properties of silicone rubber/polypropylene fibers/silica hybrid nanocomposites. J. Mech. Behav. Biomed. Mater. 2016, 57, 289-296. [CrossRef] [PubMed]

12. Ji, T.; Feng, Y.; Qin, M.; Li, S.; Zhang, F.; Lv, F.; Feng, W. Thermal conductive and flexible silastic composite based on a hierarchical framework of aligned carbon fibers-carbon nanotubes. Carbon 2018, 131, 149-159. [CrossRef]

13. Novoselov, K.S.; Geim, A.K.; Morozov, S.V.; Jiang, D.; Zhang, Y.; Dubonos, S.V.; Grigorieva, I.V.; Firsov, A.A. Electric field effect in atomically thin carbon films. Science 2004, 306, 666-669. [CrossRef] [PubMed]

14. Sreenivasulu, B.; Ramji, B.R.; Nagaral, M. A review on graphene reinforced polymer matrix composites. Mater. Today 2018, 5, 2419-2428. [CrossRef]

15. Geim, A.K.; Novoselov, K.S. The rise of graphene. Nat. Mater. 2007, 6, 183-190. [CrossRef] [PubMed]

16. Boland, C.S.; Khan, U.; Ryan, G.; Barwich, S.; Charifou, R.; Harvey, A.; Backes, C.; Li, Z.; Ferreira, M.S.; Möbius, M.E.; et al. Sensitive electromechanical sensors using viscoelastic graphene-polymer nanocomposites. Science 2016, 354, 1257-1260. [CrossRef] [PubMed]

17. Song, J.; Chen, C.; Zhang, Y. High thermal conductivity and stretchability of layer-by-layer assembled silicone rubber/graphene nanosheets multilayered films. Compos. Part A Appl. Sci. Manuf. 2018, 105, 1-8. [CrossRef]

18. Chen, C.; Pu, N.; Liu, Y.; Chen, L.; Wu, C.; Cheng, T.; Lin, M.; Ger, M.; Gong, Y.; Peng, Y.; et al. Microwave absorption properties of holey graphene/silicone rubber composites. Compos. Part B Eng. 2018, 135, 119-128. [CrossRef]

19. Tian, L.; Wang, Y.; Li, Z.; Mei, H.; Shang, Y. The thermal conductivity-dependant drag reduction mechanism of water droplets controlled by graphene/silicone rubber composites. Exp. Therm. Fluid Sci. 2017, 85, 363-369. [CrossRef]

20. Xu, H.; Gong, L.; Wang, X.; Zhao, L.; Pei, Y.; Wang, G.; Liu, Y.; Wu, L.; Jiang, J.; Tang, L. Influence of processing conditions on dispersion, electrical and mechanical properties of graphene-filled-silicone rubber composites. Compos. Part A Appl. Sci. Manuf. 2016, 91, 53-64. [CrossRef]

21. Flagg, D.H.; Mccarthy, T.J. Rediscovering silicones: MQ copolymers. Macromolecules 2016, 49, 8581-8592. [CrossRef]

22. Zhang, Y.; Zeng, X.; Lai, X.; Li, H.; Zhou, Q.; Huang, X. Suppression effect and mechanism of amine-containing MQ silicone resin on the tracking and erosion resistance of silicone rubber. ACS Omega 2017, 2, 5111-5121. [CrossRef]

23. Fang, W.; Zeng, X.; Lai, X.; Li, H.; Xie, C.; Chen, W.; Zhang, Y. Investigation of the tracking and erosion resistance of cured liquid silicone rubber containing ureido-modified MQ silicone resin. IEEE Trans. Dielectr. Electr. Insul. 2017, 23, 3668-3675. [CrossRef]

24. Di, M.; He, S.; Li, R.; Yang, D. Radiation effect of $150 \mathrm{keV}$ protons on methyl silicone rubber reinforced with MQ silicone resin. Nucl. Instrum. Methods Phys. Res. Sect. B Beam Interact. Mater. Atoms 2006, 248, 31-36. [CrossRef]

25. Chen, D.; Chen, F.; Hu, X.; Zhang, H.; Yin, X.; Zhou, Y. Thermal stability, mechanical and optical properties of novel addition cured PDMS composites with nano-silica sol and MQ silicone resin. Compos. Sci. Technol. 2015, 117, 307-314. [CrossRef]

26. Xiang, H.; Ge, J.; Cheng, S.; Han, H.; Cui, S. Synthesis and characterization of titania/MQ silicone resin hybrid nanocomposite via sol-gel process. J. Sol-Gel Sci. Technol. 2011, 59, 635-639. [CrossRef]

27. Zhao, T.; Jin, W.; Wang, Y.; Ji, X.; Yan, H.; Khan, M.; Jiang, Y.; Dang, A.; Li, H.; Li, T. Facile synthesis of graphene nanosheets via barium ferrite assisted intercalation and secondary expansion of graphite. Mater. Lett. 2018, 212, 1-3. [CrossRef]

28. Shang, Y.; Li, T.; Yin, Y.; Li, H.; Dang, A.; Zhang, L.; Chen, X.; Zhang, Y.; Xiong, C.; Zhao, T. Effect of the graphene derived from thermal reduction within matrix on the performance of graphene/poly (methyl methacrylate) composites. J. Anal. Appl. Pyrolysis 2016, 120, 215-221. [CrossRef] 
29. Shang, Y.; Li, T.; Zhu, X.; Zhang, Y.; Chen, X.; Zhao, T. Effect of the graphene sheets derived from multistep oxidized carbon nanotubes on the performance of graphene sheets/poly(methyl methacrylate) composites. J. Anal. Appl. Pyrolysis 2015, 114, 243-249. [CrossRef]

30. Guirgis, G.A.; Shens, Z.; Qtaitat, M.A.; Durig, J.R. Spectra and structure of silicon containing compounds: XXIII 1. Raman and infrared spectra, conformational stability, vibrational assignment and ab initio calculations of dimethyl vinyl chlorosilane. J. Mol. Struct. 1997, 403, 57-71. [CrossRef]

31. Shang, Y.; Li, T.; Li, H.; Dang, A.; Zhang, L.; Yin, Y.; Xiong, C.; Zhao, T. Preparation and characterization of graphene derived from low-temperature and pressure promoted thermal reduction. Compos. Part B Eng. 2016, 99, 106-111. [CrossRef]

32. Li, R.; Zhang, B.; Liu, B.; Chen, X.; Wang, G. Structure and Properties of Poly(Diphenylsiloxane-Co-Dimethylsiloxane) Modified MQ Silicone Resin. Adv. Mater. Res. 2012, 496, 109-115. [CrossRef]

33. Sun, F.; Hu, Y.; Du, H. Synthesis and characterization of MQ silicone resins. J. Appl. Polym. Sci. 2012, 125, 3532-3536. [CrossRef]

34. Sanguri, V.; Dwivedi, D.K.; Singh, N.; Pandey, N.; Pandey, J.D. Thermodynamic properties of multicomponent systems and hole theory. J. Mol. Liq. 2008, 141, 1-7. [CrossRef]

35. Song, Y.; Yu, J.; Yu, L.; Alam, F.E.; Dai, W.; Li, C.; Jiang, N. Enhancing the thermal, electrical, and mechanical properties of silicone rubber by addition of graphene nanoplatelets. Mater. Des. 2015, 88, 950-957. [CrossRef]

36. Zong, Y.; Gui, D.; Li, S.; Tan, G.; Xiong, W.; Liu, J. Preparation and thermo-mechanical properties of functionalized graphene/silicone rubber nanocomposites. In Proceedings of the 2015 16th International Conference on Electronic Packaging Technology (ICEPT), Changsha, China, 11-14 August 2015; pp. 30-34.

37. Xu, Y.; Gao, Q.; Liang, H.; Zheng, K. Effects of functional graphene oxide on the properties of phenyl silicone rubber composites. Polym. Test. 2016, 54, 168-175. [CrossRef]

38. Tian, L.; Jin, E.; Mei, H.; Ke, Q.; Li, Z.; Kui, H. Bio-inspired graphene-enhanced thermally conductive elastic silicone rubber as drag reduction material. J. Bionic Eng. 2017, 14, 130-140. [CrossRef]

39. Zhang, Y.; Yu, W.; Zhang, L.; Yin, J.; Wang, J.; Xie, H. Thermal conductivity and mechanical properties of low density silicone rubber filled with $\mathrm{Al}_{2} \mathrm{O}_{3}$ and graphene nanoplatelets. J. Therm. Sci. Eng. Appl. 2017, 10, 011014. [CrossRef]

40. Ma, W.; Li, J.; Zhao, X. Improving the thermal and mechanical properties of silicone polymer by incorporating functionalized graphene oxide. J. Mater. Sci. 2013, 48, 5287-5294. [CrossRef]

41. Shen, C.; Wang, H.; Zhang, T.; Zeng, Y. Silica coating onto graphene for improving thermal conductivity and electrical insulation of graphene/polydimethylsiloxane nanocomposites. J. Mater. Sci. Technol. 2019, 35, 36-43. [CrossRef]

42. Qiu, X.; Cai, H.; Fang, X.; Zheng, J. The improved thermal oxidative stability of silicone rubber by incorporating reduced graphene oxide: Impact factors and action mechanism. Polym. Compos. 2018, 39, 1105-1115. [CrossRef]

43. Wang, H.; Yang, C.; Liu, R.; Gong, K.; Hao, Q.; Wang, X.; Wu, J.; Zhang, G.; Hu, Y.; Jiang, J. Build a rigid-flexible graphene/silicone interface by embedding $\mathrm{SiO}_{2}$ for adhesive application. ACS Omega 2017, 2, 1063-1073. [CrossRef]

(C) 2018 by the authors. Licensee MDPI, Basel, Switzerland. This article is an open access article distributed under the terms and conditions of the Creative Commons Attribution (CC BY) license (http://creativecommons.org/licenses/by/4.0/). 